\title{
Monitoring thirty years of small water reservoirs proliferation in the southern Brazilian Amazon with Landsat time series
}

\author{
Damien Arvor $^{\mathrm{a}, *}$, Felipe R.G. Daher ${ }^{\mathrm{a}}$, Dominique Briand ${ }^{\mathrm{b}}$, Simon Dufour ${ }^{\mathrm{a}}$, Anne-Julia Rollet ${ }^{\mathrm{a}}$, \\ Margareth Simões ${ }^{c, d}$, Rodrigo P.D. Ferraz ${ }^{c}$ \\ ${ }^{a}$ Univ Rennes, CNRS, LETG - UMR 6554, F-35000 Rennes, France \\ b IRD, UMR Espace-Dev, 500 rue Jean-Francois Breton, 34090 Montpellier, France \\ ' Embrapa Solos, Rua Jardim Botânico, 1024, 22460-000 Rio de Janeiro, Brazil \\ ${ }^{\mathrm{d}}$ UERJ FEN/DESC/PPGMA, Rua São Francisco Xavier, 524, 20550-900 Rio de Janeiro, Brazil
}

\section{A R T I C L E I N F O}

\section{Article history:}

Received 21 September 2017

Received in revised form 29 January 2018

Accepted 13 March 2018

Available online 23 March 2018

\section{Keywords:}

Mato Grosso

Water reservoirs

Landsat

Time series

\begin{abstract}
A B S T R A C T
The recent decoupling of agricultural production and deforestation in the southern Amazon has been made possible thanks to (1) the adoption of intensive agricultural practices, including irrigation, and (2) the diversification of economic activities, including fish farming. Whereas this new agricultural model has brought out positive results to contain deforestation, it also implied new pressures on the environment, and especially on water resources. Many small artificial water reservoirs have been built with different uses, e.g. crop irrigation, energy generation, fish farming or livestock watering. In this paper, we introduce a method to automatically map small water bodies based on time series of Landsat images. The method was tested in the municipality of Sorriso (state of Mato Grosso, Brazil). The statistical results (Overall Accuracy $=0.872$; Kappa index $=0.745$ ) validated the efficiency of the methodology although the spatial resolution of Landsat images limited the detection of very small and linear reservoirs. In Sorriso, we estimated that the cumulated area and the number of small water reservoirs increased more than tenfold (from 153 to 1707 ha) and fivefold ( 86 to 522), respectively, between 1985 and 2015. We discuss the numerous socio-environmental implications raised by the cumulated impacts of these proliferating small reservoirs. We conclude that integrated whole-landscape approaches are necessary to assess how anthropized hydrosystems can counteract or exacerbate the socio-environmental impacts of deforestation and intensive agriculture.

(c) 2018 International Society for Photogrammetry and Remote Sensing, Inc. (ISPRS). Published by Elsevier
\end{abstract} B.V. All rights reserved.

\section{Introduction}

The southeastern Brazilian Amazon is considered as one of the world most active agricultural frontier (Campari, 2005). The rapid expansion of cultivated areas in the last thirty years has long been pointed out as a threat to the environment since it resulted in the conversion of large areas of Brazilian savannas (Cerrado) and tropical rainforests (Fearnside, 2001; Morton et al., 2006; Nepstad et al., 2006). Yet, the last decade has been marked by a decoupling between deforestation and agricultural production (Macedo et al., 2012) and between deforestation and socio-economic development (Tritsch and Arvor, 2016; Caviglia-Harris et al., 2016; Weinhold et al., 2015). During this period, deforestation rates decreased dramatically (Nepstad et al., 2009) due to (1) efficient

\footnotetext{
* Corresponding author.

E-mail address: damien.arvor@univ-rennes2.fr (D. Arvor).
}

command-and-control policies to contain deforestation (Nepstad et al., 2014), (2) market-oriented forms of regulation (e.g. the Soy Moratorium Rudorff et al., 2011; Gibbs et al., 2015; Kastens et al., 2017) and (3) the promotion of a new agricultural model based on agricultural intensification (Arvor et al., 2012) and diversification of economic activities (Arvor et al., 2018).

Although the recent release of increasing deforestation rates in the Amazon (INPE, 2017) questions the efficiency of the ongoing agricultural transition process, the last decade testified of a very dynamic frontier with a high potential for the rapid adoption of a new agricultural model engaged towards land use sustainability (Galford et al., 2013). Yet, beyond the positive impacts on deforestation, intensifying and diversifying the production also implies new pressures on natural resources. The generalization of intensive double-cropping systems requiring high amounts of agrochemicals (Arvor et al., 2017), the adoption of irrigation systems to prevent harvest losses for the second crop and the development of fish 
farming raise important concerns about the future of soil and water resources in the region (Neill et al., 2013). In this regard, the proliferation of small artificial water reservoirs to ensure crop irrigation, water livestock and farm fishes calls for special attention.

Scientific knowledge about the impacts of water reservoirs is partial since most studies focus on major dams (e.g. Adams and Hughes, 1986; Barrow, 1987; Dudgeon, 2000; Maingi and Marsh, 2002; Fearnside, 2001, 2006; Stevaux et al., 2009), especially in tropical regions such as the Amazon where the construction of numerous hydropower dams has drawn the attention of the scientific community (Fearnside, 2006; Latrubesse et al., 2017). Conversely, small reservoirs have received less attention despite several studies led in various regions of the world like Australia (Nathan and Lowe, 2012), South Africa (Hughes and Mantel, 2010), Europe (Cudennec et al., 2004, 2017), the USA (Ramireddygari et al., 2000) and Brazil (Mamede et al., 2012; Malveira et al., 2012) have shown that their multiplication can generate significant cumulated effects on chemical fluxes (e.g. Powers et al., 2014), fish communities (e.g. Santucci et al., 2005) and hydrological cycles (e.g. Habets et al., 2014). In this specific regard, various studies concluded that a high number of dams, although small when considered individually, can have similar or even greater impacts than one single large dam (Callow and Smettem, 2009; Malveira et al., 2012; Gütner et al., 2004).

Whereas methods and models to assess the individual and cumulated impacts of dams exist (Habets et al., 2014), mapping and counting the small artificial reservoirs at regional scale still appears as a major bottleneck for this type of application (Lehner et al., 2011). This point is of extreme importance since the spatial distribution of the water bodies (i.e. density, position in the basin, etc.) is known to be crucial to assess their cumulated effects (Deitch et al., 2013). In this regard, although the spatial resolution of satellite images is often inadequate to map small water bodies (Lowe et al., 2005; Rodrigues et al., 2012; de Toledo et al., 2014), remote sensing data are relevant to rapidly and homogeneously determine the number and extent of artificial reservoirs on large areas. Landsat (TM, ETM + and OLI) data have been especially used for this purpose due to its fine spatial resolution $(30 \mathrm{~m})$ that enables to detect small water bodies, including farm dams. Images are then usually interpreted individually using visual inspection (Malveira et al., 2012) or supervised classifiers (e.g. decision trees or random forests) or classification rules applied on calibrated bands or spectral indices (Rodrigues et al., 2012; Bhagat and Sonawane, 2011; Acharya et al., 2016; Ko et al., 2015; Tulbure and Broich, 2013; Jones et al., 2017). Such approaches led to successful results but may be difficult to apply in other areas (i.e. classification rules need to be adapted), especially in tropical areas with few available images (e.g. due to high cloud cover rates). The analysis of time series of optical remote sensing data has then been recognized for its great potential to characterize environmental phenomena, describing trends as well as discrete change events (Gómez et al., 2016). Such multi-temporal approaches have been used for land cover (e.g. Inglada et al., 2017; Hansen and Loveland, 2012), forest (e.g. Hansen et al., 2013; Carreiras et al., 2014) and crop monitoring (e.g. Waldner et al., 2015). In regard to hydrological applications, Tulbure and Broich (2013), for example, classified 12 years of Landsat data to map the spatio-temporal dynamics of water bodies in southeastern Australia. More recently, Pekel et al. (2016) processed three millions of Landsat images in order to map surface water bodies at global scale. Nonetheless, Jones et al. (2017) considered this data unsuitable for monitoring very small reservoirs (smaller than $5.1 \mathrm{ha}$ ). Yet, in spite of these recent important advances, the automatic detection of small water bodies for local and regional applications remains challenging to date.
The objectives of the present paper are twofold. We first introduce a fully automatic methodology to map water bodies at local and regional scale based on Landsat time series. Second, we monitor the expansion of small water reservoirs from 1985 to 2015 in the municipality of Sorriso (State of Mato Grosso, Brazil) in order to characterize the ongoing process of agricultural transition.

\section{Study area}

The study area is located in the southern Amazon Brazilian state of Mato Grosso (Fig. 1). This state has long been studied due to the dramatic land use changes that occurred there since the 1970s, when the federal government decided to support the development of an extensive commodity-oriented agriculture (Arvor et al., 2013, 2018). The agricultural expansion in Mato Grosso has led to severe environmental impacts, especially with regard to deforestation (Fearnside, 2001; Morton et al., 2006). In the 2000s, an agricultural intensification and diversification process was initiated with the objective to increase productivity, limit economic vulnerability to monoculture and contain deforestation (Arvor et al., 2012; Kastens et al., 2017; VanWey et al., 2013). As a major result, deforestation decreased rapidly after 2005 while agricultural production continued to increase (Macedo et al., 2012; Nepstad et al., 2014). The state of Mato Grosso became national leader in the production of soybean, maize and cotton (IBGE, 2017) and third in fish production (the national leader being the state of Rondônia, also in the southern Amazon). The development of the fish industry in Mato Grosso, and more generally in the southern Amazon, was supported by important public policies. In 2015, the Ministry of Fisheries and Aquiculture (Ministério da Pesca e Aquicultura, MPA) launched the Safra da Pesca e Aquicultura (PSPA) program with the objective to support the sustainable development of fishing and aquaculture activities. In this program, $\mathrm{R} \$ 2$ billion of incentives were available through credit lines for small, medium and large producers to improve the production and productivity of fishing activities (FAMATO, 2014).

In Mato Grosso, the municipality of Sorriso serves as the best example. Sorriso was founded in 1986 and covers an area of $9.329 \mathrm{~km}^{2}$ located along the BR-163 Cuiabá - Santarém transamazonian road (Fig. 1). Sorriso is known as the main soybean and maize producer at national scale and, for a few years, fish farming is also considered with special attention due to easy access to credits. In consequence, Sorriso was recently ranked fourth at national level with a total fish production of 10.679 tons (Table 1 ).

\section{Data and methods}

\subsection{Data}

The municipality of Sorriso is covered by four Landsat scenes, i.e. Path/Row = 226/068, 226/069, 227/068, 227/069 (Fig. 1). For these four scenes, we selected all geometrically corrected (L1T) Landsat-5 and Landsat-8 images with less than 50\% cloud cover for seven years: 1985, 1990, 1995, 2000, 2005, 2010 and 2015. Our study is thus focused on the production of 28 maps (4 scenes $\times 7$ years), hereafter named "scene-year". If less than 10 images were available for a given scene-year, we also acquired images from the previous year in order to collect a larger dataset. Such case especially happened for the years before 2000. At the end, we acquired more than 10 images for each scene-year (except in 1985 for the scene $227 / 069$ where only 7 images were available on the 1984-1985 time period) summing a total of 361 images (Table 2). These images were ordered through the USGS ESPA Ordering Interface (http://espa.cr.usgs.gov website) where we also 


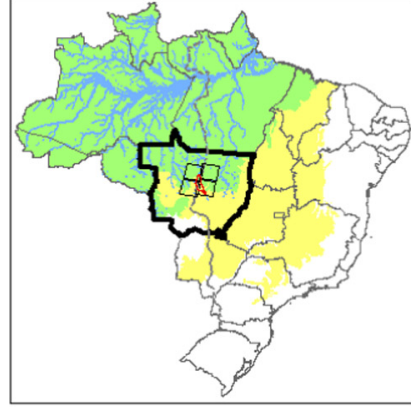

Legend

$\square$ Brazilian st ates

$\square$ Mato Grosso

Am azon biome

Cerrado biome

Main rivers in the Amazon basin

=-m BR 163 road

$\square$ Landsat scenes

$\square$ Municipality of Sorriso

Urban center of Sorriso

Artificial water reservoirs
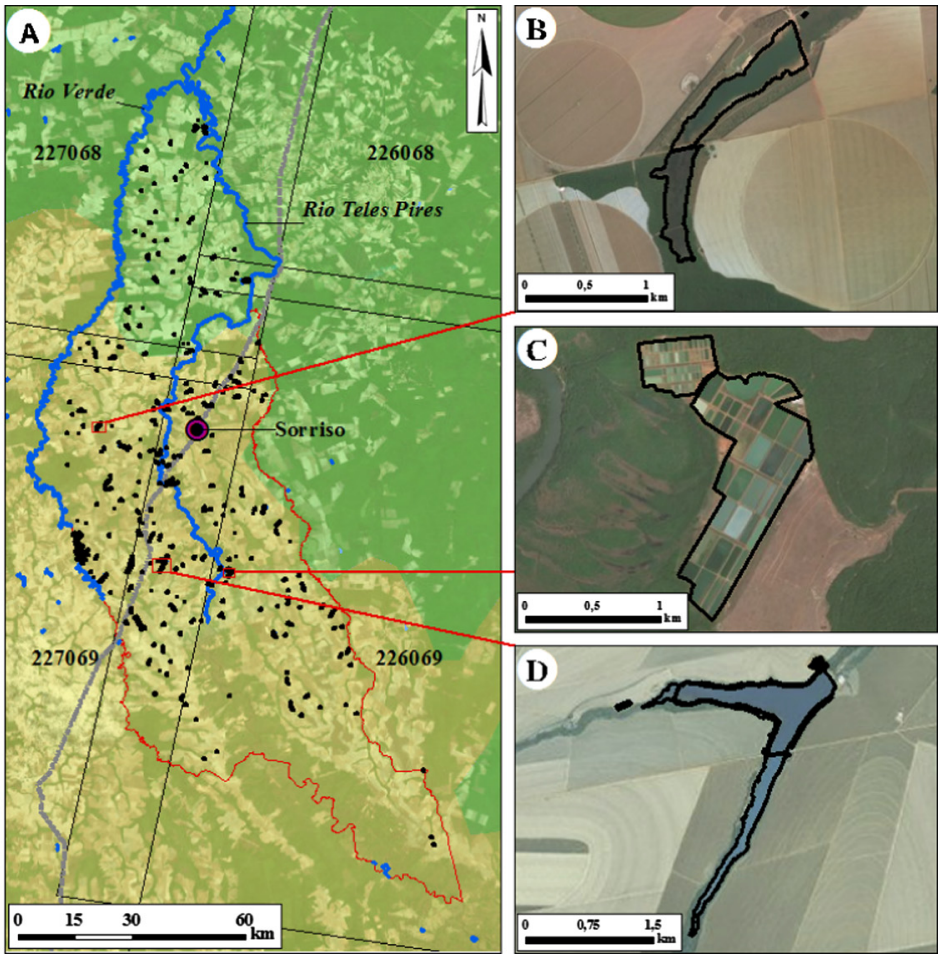

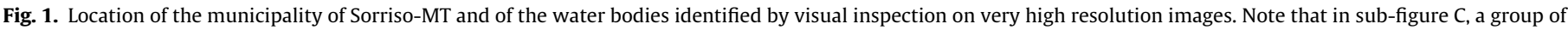
small water tanks are identified as part of a unique water body.

Table 1

Main agricultural and fish production and national ranking for the state of Mato Grosso and the municipality of Sorriso in 2015 (IBGE, 2017 ).

\begin{tabular}{|c|c|c|c|c|}
\hline & \multicolumn{2}{|c|}{ Mato Grosso } & \multicolumn{2}{|c|}{ Sorriso } \\
\hline & Prod. (Tons) & Nat. Rank & Prod. (Tons) & Nat. Rank \\
\hline Soybean & 27.850 .954 & $1^{\circ}$ & 1.951 .710 & $1^{\circ}$ \\
\hline Maize & 21.353.295 & $1^{\circ}$ & 2.619 .690 & $1^{\circ}$ \\
\hline Cotton & 2.373 .581 & $1^{\circ}$ & 47.430 & $23^{\circ}$ \\
\hline Fish & 47.437 & $3^{\circ}$ & 10.679 & $4^{\circ}$ \\
\hline
\end{tabular}

Table 2

Summary of Landsat images processed for the mosaicked classifications at 7 different time periods.

\begin{tabular}{|c|c|c|c|c|c|}
\hline & \multicolumn{4}{|c|}{ Scenes } & \multirow[b]{2}{*}{ Total } \\
\hline & $226 / 068$ & $226 / 069$ & $227 / 068$ & $227 / 069$ & \\
\hline 1984-1985 & 12 & 10 & 10 & 7 & 39 \\
\hline 1989-1990 & 15 & 16 & 12 & 11 & 54 \\
\hline 1994-1995 & 12 & 15 & 11 & 11 & 49 \\
\hline 1999-2000 & 14 & 17 & 11 & 10 & 52 \\
\hline 2005 & 12 & 11 & 15 & 13 & 51 \\
\hline 2010 & 11 & 11 & 13 & 13 & 48 \\
\hline 2015 & 18 & 16 & 18 & 16 & 68 \\
\hline Total & 94 & 96 & 90 & 81 & 361 \\
\hline
\end{tabular}

had access to the cloud-shadow Fmask product (Zhu and Woodcock, 2012).

\subsection{Classification of water bodies}

Once the data were acquired (step 0), the method to process the images was made of five main processing steps (Fig. 2): (1) data were pre-classified, (2) two indices were computed for each scene-year based on the analysis of time series, (3) the indices were mosaicked on the entire area, (4) annual water masks were produced and (5) inter-annual transition rules were applied.
Finally, the method includes a validation step (6) to assess the accuracy of the produced maps.

\subsubsection{Landsat Spectral Classifier (LSC) pre-classifications}

All images were firstly automatically calibrated in Top-ofAtmosphere reflectance according to the methods described in Chander et al. (2009) for Landsat-5 images and by USGS (2016) for Landsat-8 images. Secondly, the images were pre-classified using a method hereafter named Landsat Spectral Classifier (LSC) (Baraldi et al., 2006). This method has initially been designed for Landsat-5 (TM) and Landsat-7 (ETM+) images but its application 


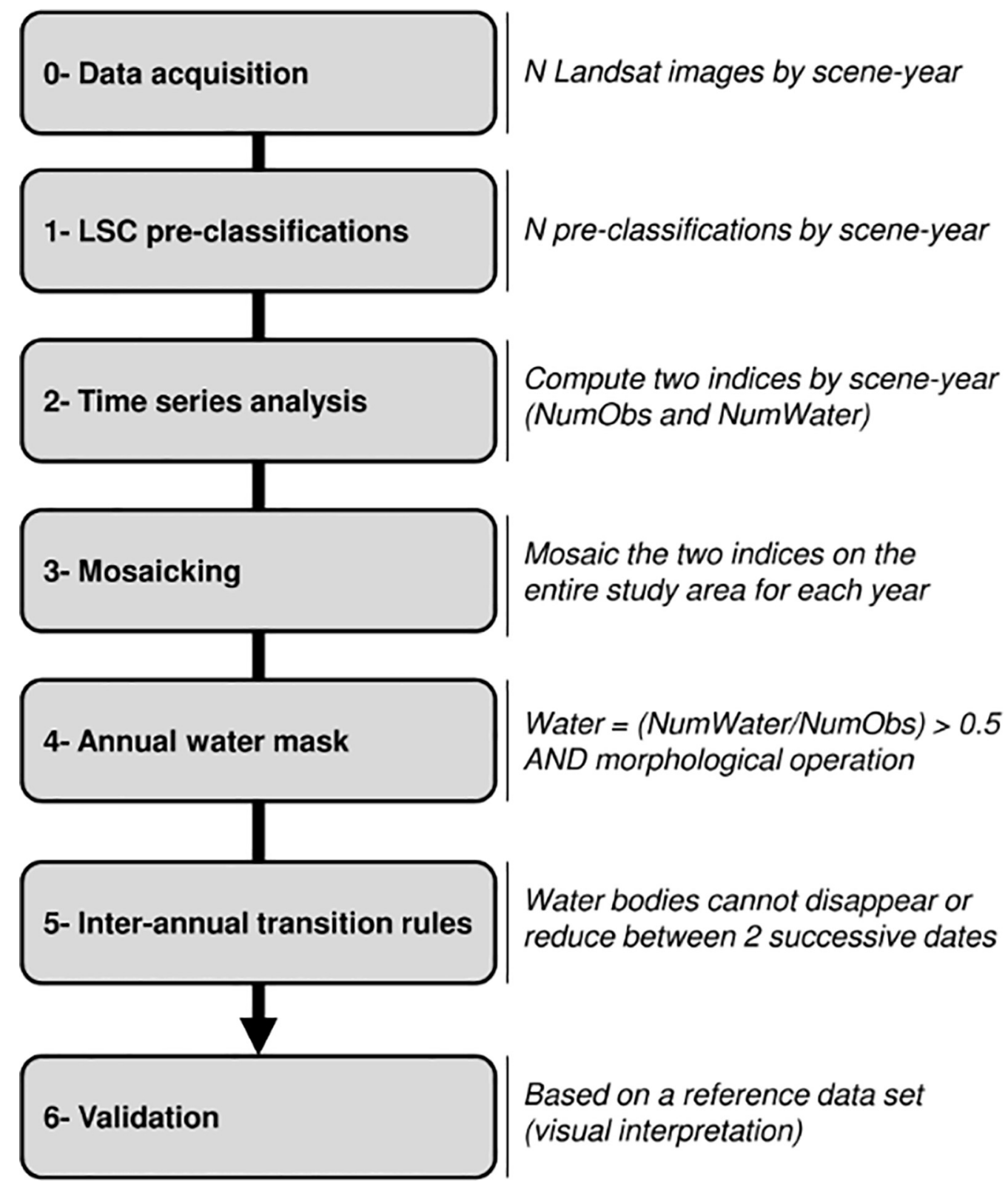

Fig. 2. Diagram of the proposed methodology to classify water bodies based on Landsat time series.

to Landsat-8 (OLI) is possible thanks to the continuity between Landsat satellites (Irons et al., 2012; She et al., 2015). The method assigns pixels to spectral categories (hereafter named LSC classes) exclusively based on spectral rules. It is worth noting that these spectral categories (up to 46 LSC classes are discriminated) do not correspond to true land cover classes but should rather be considered as descriptions of spectral signatures. For example, the SVHNIR class refers to Strong Vegetation with High Near-Infrared values. This label does not give information on the final land cover class (e.g. it is not possible to say if it corresponds to a forest or a crop land cover). This is the reason why we refer to the product of the LSC method as a LSC pre-classification.

The LSC pre-classification contains an "unclassified" class for pixels whose spectral signature does not correspond to any of the 45 other LSC classes. After visual inspection, it appeared that this class usually corresponded to cloudy pixels. Even in that case, it was not a major issue since clouds were already detected by the cloud-shadow Fmask (Zhu and Woodcock, 2012). Nonetheless, it also happened that cloud-free pixels were assigned to this "unclassified" class, thus meaning that potentially useful cloud-free pixels were discarded from the analysis. This was a problem since we cannot afford to discard cloud-free pixels from the classification process in tropical areas affected by high cloud cover rates. To address this issue, samples of 500 pixels per LSC class already encountered in the image (except cloudy classes) were randomly selected and used to train a Support Vector Machine (SVM) in order to assign a LSC class to these cloud-free "unclassified" pixels.

\subsubsection{Time series analysis}

For each scene-year, we organized a time series of $N$ LSC preclassifications where each pixel was thus described by $N$ observations, each observation referring to a LSC class. These time series were then processed to extract two indices.

The NumObs index value expresses the number of times a pixel has been observed in a time series. Here, we considered a pixel was observed when it was not classified as cloud or shadow. Cloud and 
shadow pixels were defined by the Fmask (Zhu and Woodcock, 2012) and by the following LSC classes: "Thick Cloud" (TKCL), "Thin Cloud (TNCL)", "Snow" (SN), "Snow or Ice (ICSN)", "Shadow Clouds" (SHCL) and "Shadow Snow" (TWASHSN).

The NumWater index value expresses the number of times a pixel was classified as water in a time series of LSC preclassifications. Although the labels of the LSC classes described in Baraldi et al. (2006) are not explicit in terms of land cover, potential corresponding land cover classes are proposed. Here we considered that only five spectral categories correspond to water bodies: "Deep Water or Shadow" (DPWASH), "Shallow Water or Shadow" (SLWASH), "Turbid Water" (TWA), "Wetland" (WE) and "Shadow Area with Vegetation" (SHV) (which can possibly refer to non-forested wetlands; Baraldi et al., 2006). According to the authors, all these LSC classes may be confused with shadow areas but, in our case, we considered that they were more likely to represent water pixels since shadows were already detected by the Fmask product (Zhu and Woodcock, 2012).

\subsubsection{Mosaicking}

The two index images (NumObs and NumWater) were produced for each scene-year of the analysis. We then performed a mosaicking to obtain two complete index images of the municipality of Sorriso for each year. The mosaicking was based on the NumObs index. It means that, in the overlaying parts between two (or more) adjacent images where pixels were described by two (or more) time series, we only kept the NumWater and NumObs values corresponding to the time series with the highest number of observations (i.e. the highest NumObs value).

\subsubsection{Annual water masks}

Based on these indices, we produced water masks for each year of the study period. The water masks were computed by identifying water pixels based on the ratio between the NumWater and NumObs index. Pixels with a ratio value greater than or equal to $50 \%$, i.e. predominantly classified as water in a time series of $N$ LSC pre-classifications, were considered as water pixels. In addition, we computed a dilation-erosion morphological operation (with a $3 \times 3$-pixels kernel) in order to retrieve more realistic envelopes of water bodies and remove noisy pixels (i.e. isolated land pixels identified in water bodies).

\subsubsection{Inter-annual transition rules}

Finally, two inter-annual transition rules were applied on the pluri-annual time series of water masks using an object-based approach, i.e. water bodies were considered as separated image objects. Both rules were based on the hypothesis that farm dams and excavated tanks are built to last on a long-term and are thus not expected to disappear neither to reduce over time.
In this regard, the first rule implied that water bodies detected at year $t$ but not detected at year $t+5$ (i.e. water bodies that have disappeared between two dates) were discarded from the water mask of year $t$.

The second rule implied to consider the largest envelope of water bodies observed with different boundaries at different dates. We thus considered that a water body detected at year $t$ cannot be smaller than its corresponding water body detected at year $t-5$, i.e. it cannot reduce between two dates. They are thus merged to obtain the final water body observed at year $t$.

\subsubsection{Validation}

The methodology was validated on the final water mask of year 2015. The validation was based on a reference dataset where all run-of-river dams and excavated tanks in Sorriso were manually mapped by visual inspection on Google Earth (Fig. 1). Verifications based on 2016 Sentinel-2 images were also made in order to ensure correct delineation of a few dubious water bodies. All water bodies separated by less than $60 \mathrm{~m}$ were then merged together in order to homogenize the reference dataset. Indeed, excavated tanks in fish farms were sometimes delineated individually (i.e. each tank is delineated separately) or collectively (i.e. a group of numerous water tanks is delineated in a unique polygon, Fig. 1, C). The $60 \mathrm{~m}$ threshold was used because two water bodies separated by less than $60 \mathrm{~m}$ in the classification will automatically be merged due to the dilation-erosion process (see Section 3.2.4). At this stage, the reference dataset was made of $N=396$ artificial water reservoirs summing a cumulated area of $17.30 \mathrm{~km}^{2}(1730$ ha). It is worth noting that the Canoa Quebrada hydropower dam located along the Rio Verde river (area of $6.02 \mathrm{~km}^{2}, 602$ hectares) was not considered here since our focus was on small water dams.

This reference dataset was used to assess the accuracy of the 2015 water mask. For this purpose, we defined a $500 \mathrm{~m}$ buffer around each water reservoir of the reference dataset to get samples of terrestrial land cover class. We then randomly selected 1000 points of water class (within the water reservoirs) and 1000 points of land class (in the buffer areas) (Fig. 3). We ran this process 100 times in order to assess the robustness of our results. We then produced the 100 corresponding confusion matrices (Congalton, 1991) and their associated statistical indices, i.e. overall accuracy, kappa index, producer's and user's accuracy. We finally computed an average confusion matrix based on the mean values of these indices and plotted their density functions.

Beyond the confusion matrix, we also assessed the potential of the method to estimate the cumulated area $(C A W B)$ and the number of artificial water bodies (NumWB) for an efficient monitoring of the evolution of water reservoirs since 1985. In this regard, the classification of natural water bodies as water may lead to high uncertainties, with expected overestimations for both metrics. To address this uncertainty issue, we preferred to calculate a range

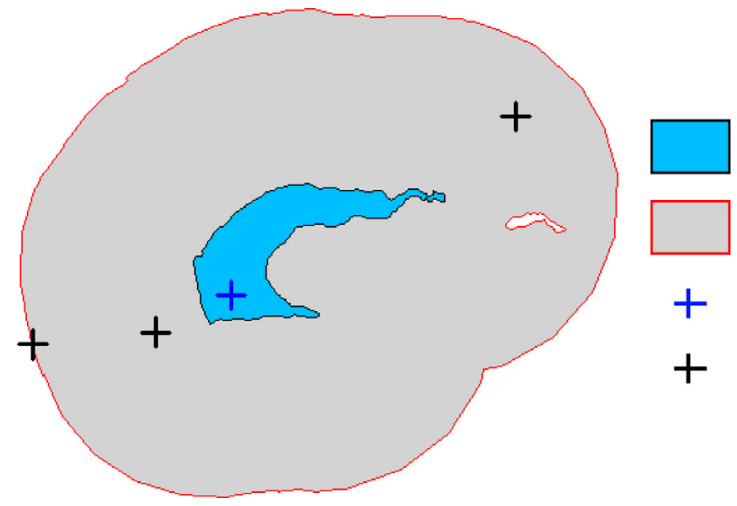

Water reservoir

$500 \mathrm{~m}$ buffer around the reservoir

Randomly selected point in « Water » class

Randomly selected points in " Land " class

Fig. 3. Example of randomly selected points for validation in both water and land classes. 
of values based on low and high estimates of both metrics for each year of the study period.

The high estimates were obtained by calculating $C A W B$ and NumWB metrics for the entire area of Sorriso, discarding only the two largest rivers in Sorriso (i.e. "Rio Teles Pires" and "Rio Verde") which appeared clearly in the final water masks. On the contrary, the low estimates were computed on a sub-area by applying a $2000 \mathrm{~m}$ buffer around these two major rivers and removing all water bodies fully or partially located inside (i.e. intersecting) that buffer. This threshold was defined to discard most potential natural water bodies along these rivers that may have been classified as water bodies. By doing so, we obviously also removed many artificial reservoirs $\left(N=54\right.$, CumulatedArea $\left.=3.94 \mathrm{~km}^{2}\right)$ so that the corresponding reference dataset contained only $N=342$ artificial water reservoirs for a total area of $13.36 \mathrm{~km}^{2}$ (1336 ha) of artificial water bodies. At the end, low and high estimates give a range of values for both $C A W B$ and NumWB metrics that enable to monitor the development of water reservoirs in Sorriso.

\section{Results}

\subsection{Classification accuracy}

A time series of LSC pre-classifications is shown in Fig. 4 and illustrates the capacity of the Landsat Spectral Classifier to automatically classify water pixels. These pre-classifications were analyzed to compute the NumObs and NumWater indices for each scene-year, which were then mosaicked annually on the entire study area. In the example shown in Fig. 5, it appeared that (1) all pixels of the mosaicked image were observed between 7 and 18 times in the year 2015 and (2) a pixel was classified as water 16 times at the most. Based on these indices, we computed annual water masks and applied the inter-annual rules to produce final maps of water bodies in the municipality of Sorriso (Fig. 6). When visually compared to the reference dataset, most water reservoirs appeared to be correctly delineated (Fig. 6 A, C, and D). Main errors mainly concerned very small and linear water bodies (Fig. 6B) whose delineation (and thus area) could not be accurately captured (estimated) at Landsat resolution.

From a statistical point-of-view, the results validated the potential of the methodology to automatically and efficiently detect water reservoirs in the study area. The average confusion matrix (Table 3) was characterized by high values for overall accuracy $(\mathrm{O} . \mathrm{A} .=0.872)$ and Kappa index $(\mathrm{K}=0.745)$. The density functions of the main statistical indices obtained after running the validation procedure 100 times indicated a low variability, thus confirming the robustness of the methodology (Fig. 7). Most errors were omissions, i.e. water pixels not detected on Landsat images. In this regard, our results indicated that $77.5 \%$ of the $N=396$ water bodies of the reference dataset were detected by the method, i.e. at least one pixel had been classified as water. Considering that only $85.6 \%$ of all water bodies of the reference dataset have been detected as water at least once in a time series of LSC

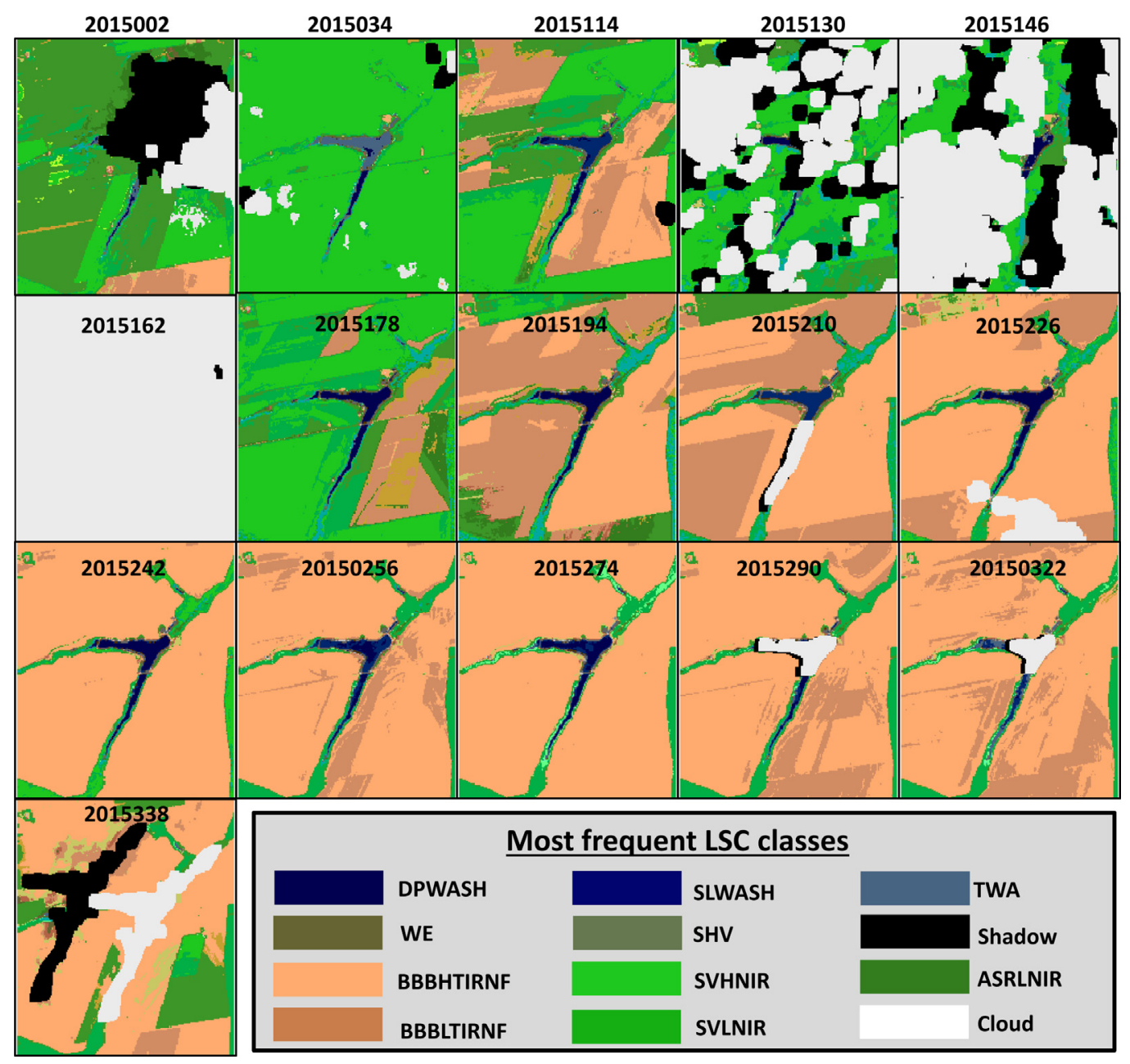

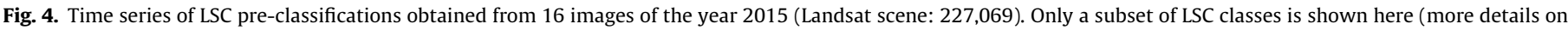
the meaning of the LSC classes are in Baraldi et al. (2006)). 


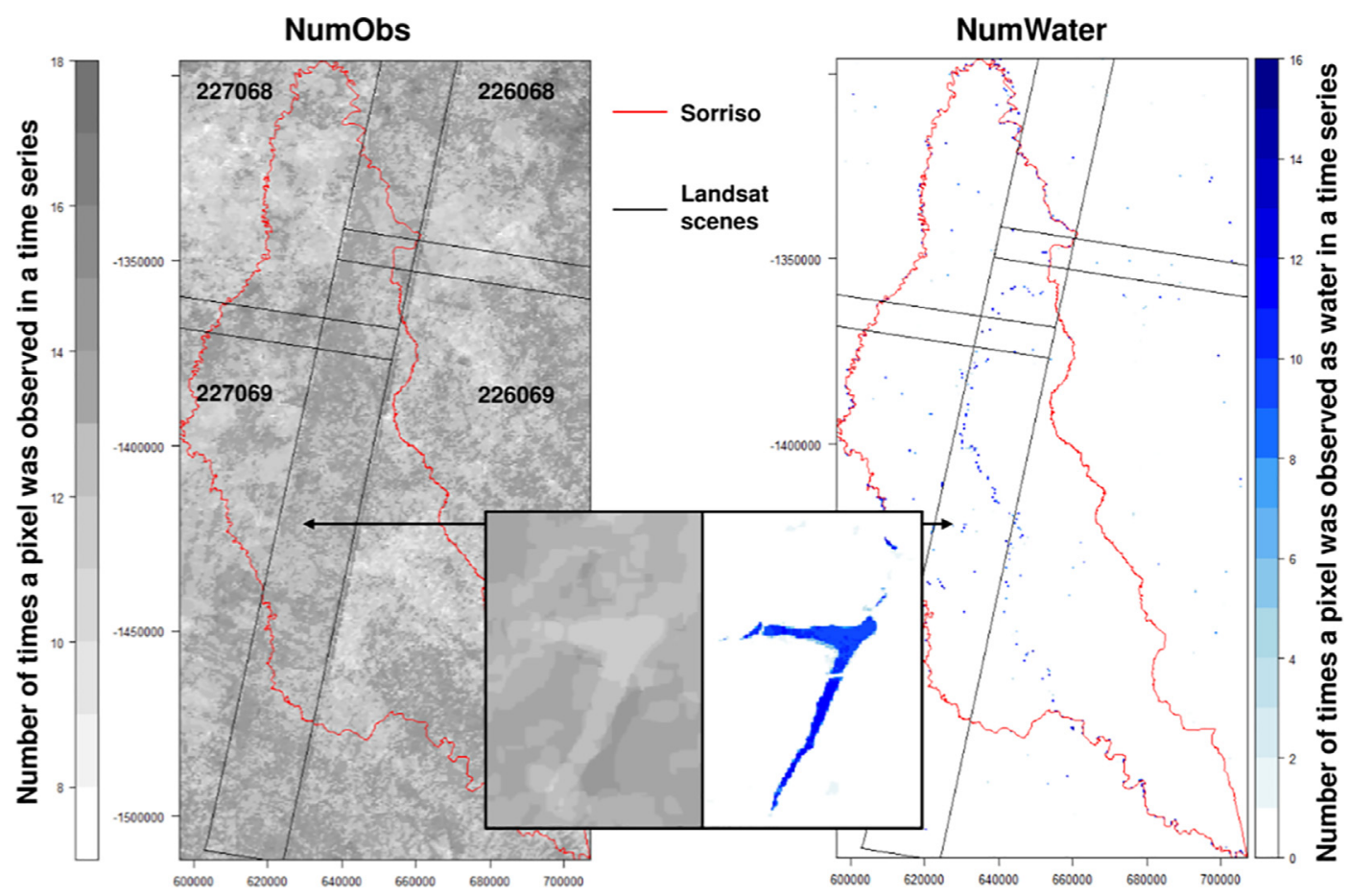

Fig. 5. Mosaicked maps of NumObs and NumWater indices obtained from time series of LSC pre-classifications of the year 2015.
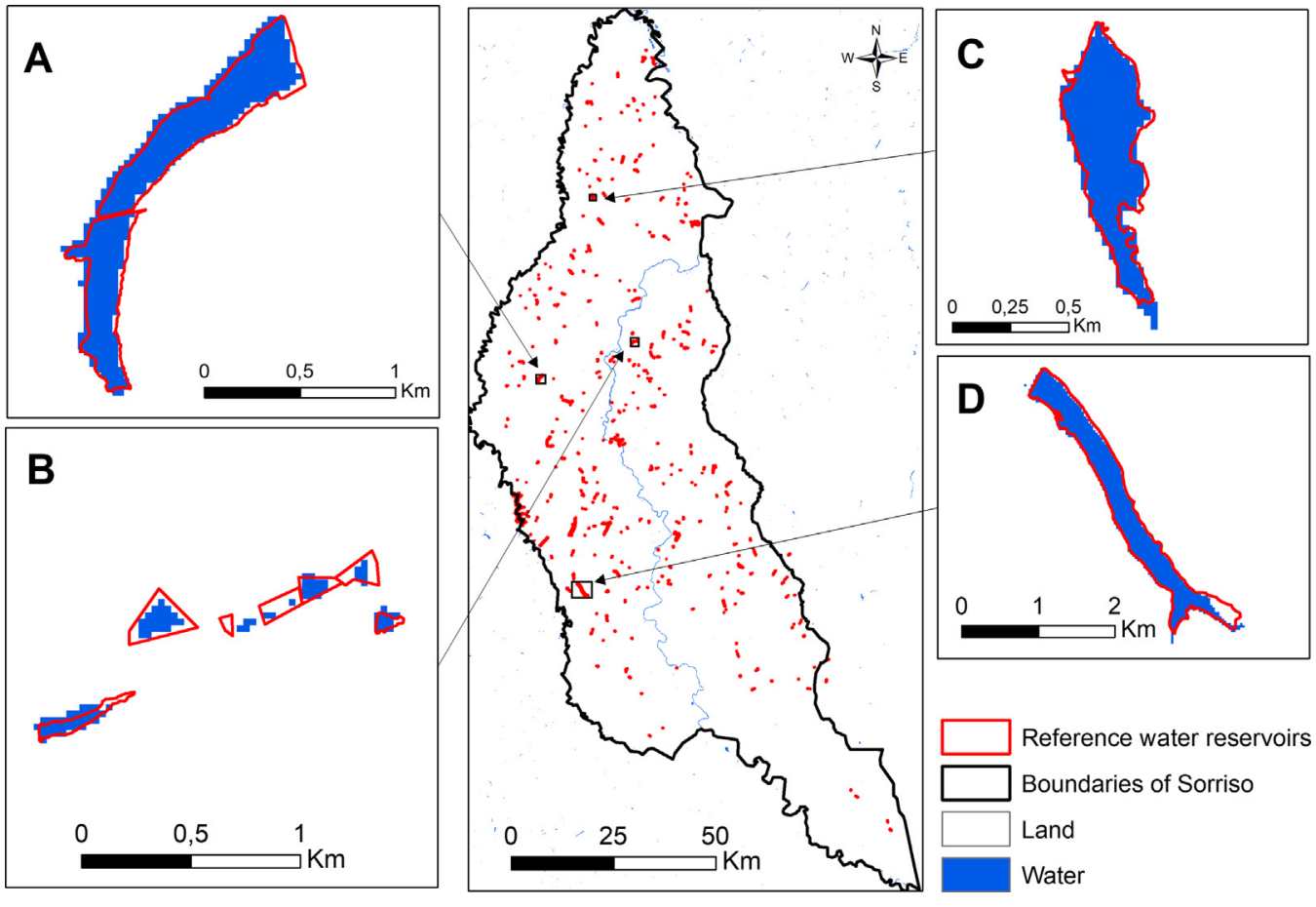

Fig. 6. Final water mask of Sorriso (MT) for year 2015.

pre-classifications (NumWater $>0$ ), this result $(77.5 \%)$ represents a good approximation of the best potential result that could be achieved by such approach. After a visual inspection focused on non-detected water bodies, we identified three main causes of omission errors: (1) water bodies were not filled in water during the entire year (e.g. dams under construction in 2015) and thus could not be detected as water, (2) the largest omitted water body $\left(97,000 \mathrm{~m}^{2}\right)$ was adjacent to the Teles Pires river and had thus been discarded when we removed the two major rivers from the analysis and, (3) most important, small water bodies and/or water bodies with a linear shape were difficult to identify at Landsat resolution. This last case was expected since it is usually agreed that the image resolution must be $1 / 2$ to $3 / 4$ the size of the smallest objects of interest in the scene (Marceau et al., 1994). On the other hand, few commission errors were detected in the confusion matrix. These errors were due to water reservoirs manually 
Table 3

Average confusion matrix of the 2015 water mask (Reference data are in rows and classification data are in columns)

\begin{tabular}{lccc}
\hline & Land & Water & Producer's Accuracy \\
\hline Land & 989 & 11 & 0.989 \\
Water & 244 & 756 & 0.756 \\
User's Accuracy & 0.802 & 0.985 & \\
Overall Accuracy & 0.872 & & \\
Kappa index & 0.745 & & \\
\hline
\end{tabular}

delimited based on dry season high-resolution images so that the boundaries may not exactly correspond to the boundaries observed on a time series of Landsat images.

Nonetheless, although the commission errors were little, the cumulated areas $(C A W B)$ and number $(N u m W B)$ of water bodies in the entire area of Sorriso (high estimates) were highly overestimated. The classification identified $C A W B=20.28 \mathrm{~km}^{2}$ (2028 hectares) across $N u m W B=611$ water bodies, i.e. much more than in the reference dataset $\left(C A W B=17.30 \mathrm{~km}^{2} ; 1730\right.$ hectares across $N u m W B=396$ water reservoirs) (Table 4). Three main reasons can explain such overestimation in both metrics. First, groups of water tanks were considered as part of a unique water body in the reference dataset (see Section 3.2.6 and Fig. 1,C) while the classification often identified many disconnected pixels, thus increasing the number $N$ of water bodies (although usually underestimating the area) (see Fig. 6, B for an example). As a confirmation of this hypothesis, it is worth mentioning that the 307 water bodies of the reference dataset that were correctly detected by the method actually corresponded to 365 water bodies in the classification. Second, the first inter-annual transition rule aiming at discarding small water bodies erroneously classified as artificial water body (commission errors) by checking their existence in following years could not be applied for the 2015 classification since we did not have water masks for the following years. In that case, the number of small water bodies may be overestimated although we consider that the high number of available images (between 16 and 18, Table 2) and observations (high NumObs values) for that year should compensate for this problem. Third and most important, the mapping of natural water bodies often located along the two major rivers increased dramatically the cumulated areas (by at least $3 \mathrm{~km}^{2}$ ). At the end, these problems were expected and justified the need to also produce low estimates for both metrics.

These low estimates were produced by removing water bodies located in a buffer of $2000 \mathrm{~m}$ around the major rivers, thus discarding a large part of natural water bodies. In that case, the classification identified a cumulated area of $C A W B=13.86 \mathrm{~km}^{2}$ across $N u m W B=433$ water bodies (Table 4). While the NumWB is still overestimated (mainly due to the high fragmentation of water bodies in fish farms), the estimated area represents a good approximation of the reference value $\left(C A W B=13.36 \mathrm{~km}^{2}\right)$.

\subsection{Thirty years of development of artificial water reservoirs}

The production of the annual water masks enabled to monitor the rapid expansion of water bodies in Sorriso during the last thirty years. As an example, the Fig. 8 introduces two areas of Sorriso that illustrate two different cases of development. In the first case (Fig. 8, left), the development of water surfaces resulted from the multiplication of small farm dams from one in 1990 to four in 2015. In the second case (Fig. 8, right), it resulted from successive expansion stages of a farm dam between 1990 and 2015.

At the scale of the municipality of Sorriso, the cumulated area increased from 153 hectares (mean value between the low and high estimates) in 1985 to 1707 hectares in 2015, i.e. the area of a medium-size farm in the region (Fig. 9, top). The cumulated area thus increased more than tenfold in thirty years. The results showed an especially rapid proliferation after 2000 corresponding to the period of agricultural intensification in the region (Arvor et al., 2012), which was partially based on irrigation thus requiring increased access to water resources.

The number of water bodies also increased rapidly during the study period, from 86 to 522 (mean values of 1985 and 2015) (Fig. 9, bottom). Although these numbers must be considered carefully due to the reasons introduced in the previous section
Overall Accuracy and Kappa

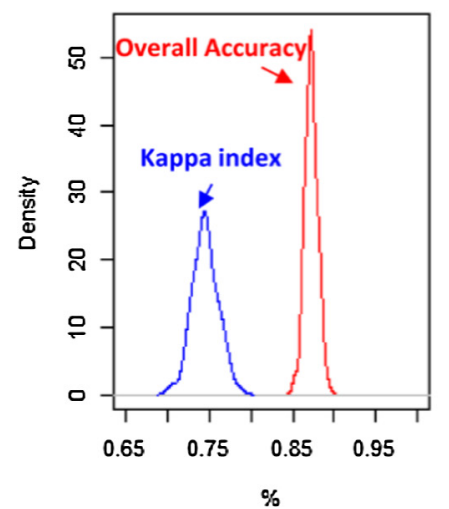

Producer's Accuracy

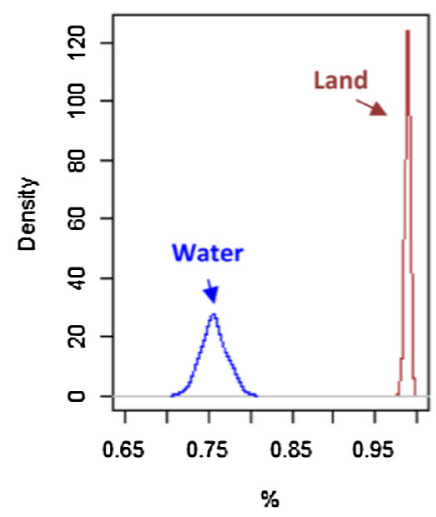

User's Accuracy

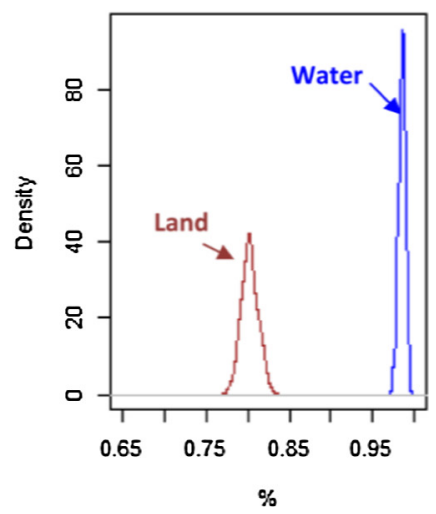

Fig. 7. Density functions of the main statistical indices computed to validate the 2015 water mask.

Table 4

Low and high estimates of cumulated area $(C A W B)$ and number (NumWB) of water bodies in Sorriso in 2015.

\begin{tabular}{|c|c|c|c|c|}
\hline & \multicolumn{2}{|c|}{ High estimate } & \multicolumn{2}{|c|}{ Low estimate } \\
\hline & CAWB & NumWB & CAWB & NumWB \\
\hline Reference & $17.30 \mathrm{~km}^{2}$ & 396 & $13.36 \mathrm{~km}^{2}$ & 342 \\
\hline Classification & $20.28 \mathrm{~km}^{2}$ & 611 & $13.86 \mathrm{~km}^{2}$ & 433 \\
\hline
\end{tabular}



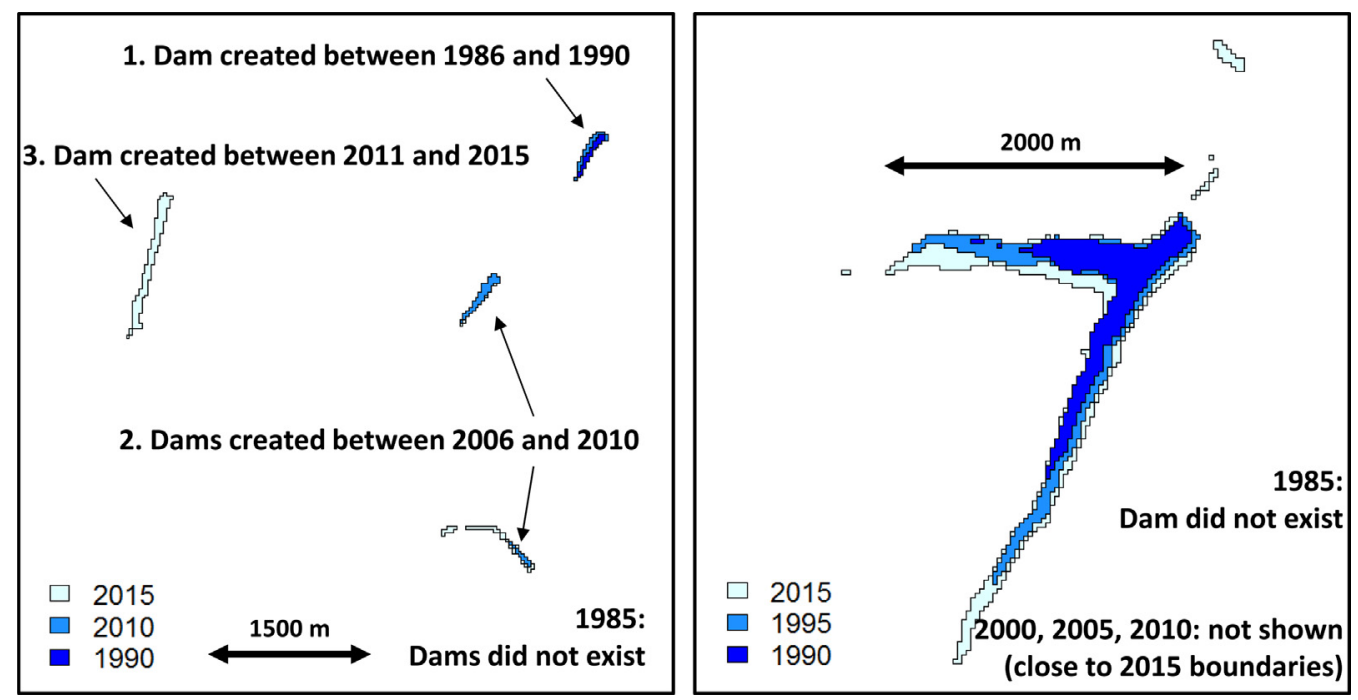

Fig. 8. Spatial evolution of artificial water bodies between 1985 and 2015 in two areas of Sorriso.

\section{Cumulated area of water bodies}

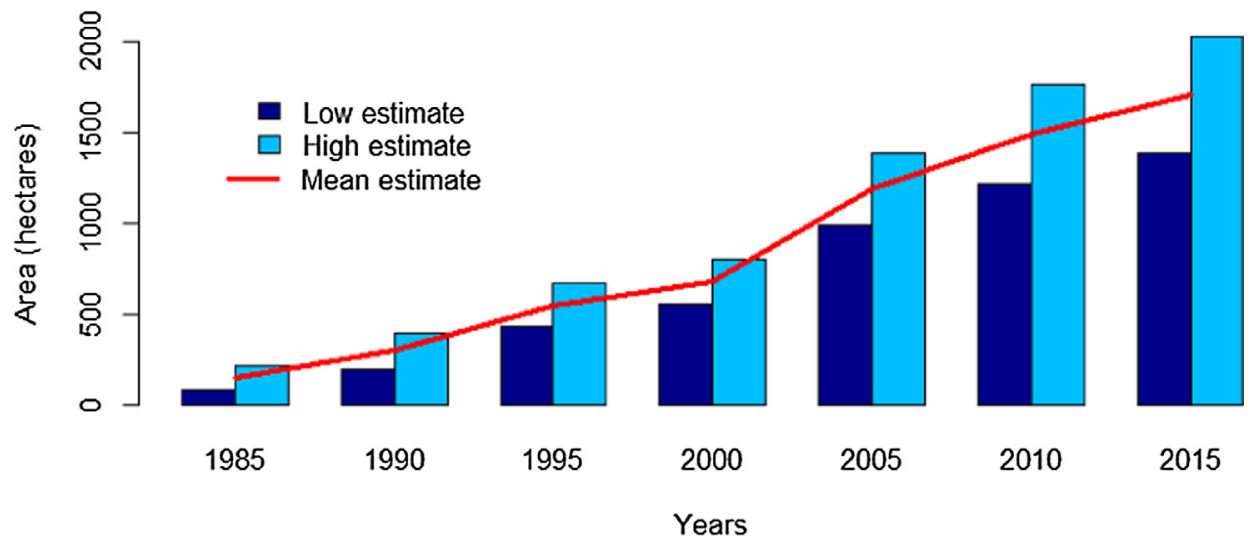

\section{Number of water bodies}

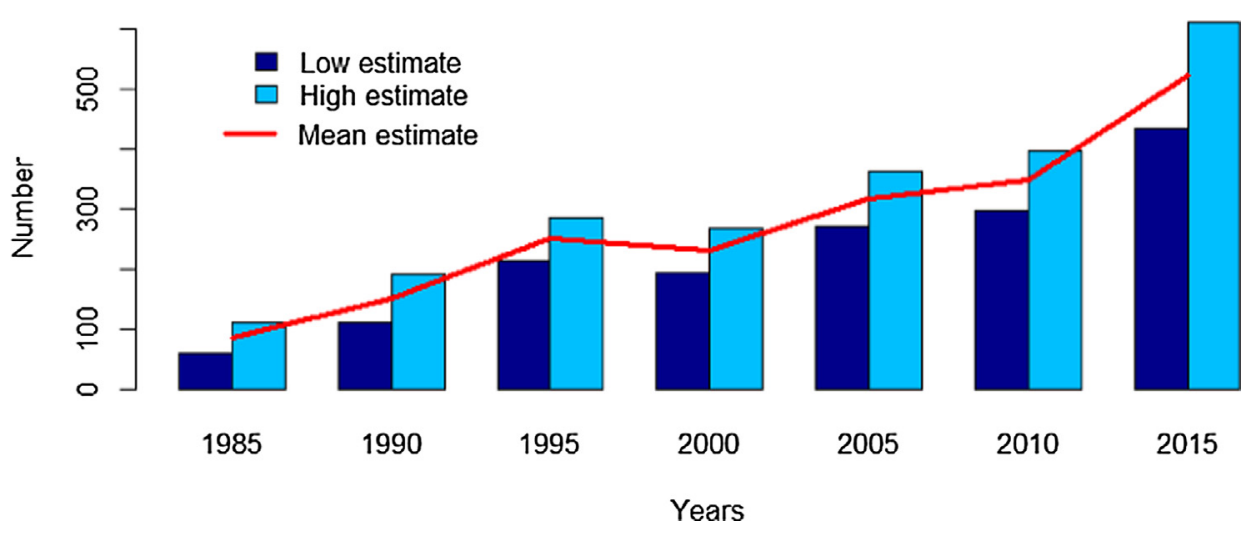

Fig. 9. Temporal evolution of the cumulated area and number of water bodies in Sorriso between 1985 and 2015.

(e.g. high fragmentation and inclusion of natural water bodies in the final counting), the results showed interesting trends that deserve to be analyzed. Firstly, we identified more water bodies in 1995 than in 2000, what was not expected because of the first inter-annual rule (which was designed to remove water bodies detected in 1995 but not observed in 2000). After visual inspection, it appeared that few water bodies were actually classified in 1995 and 2000 but not in 2005 (and following years), thus explaining why they disappeared from the 2000 map but not from the 1995 map. In this regard, the possible destruction of water dams should 
be further investigated. Additionally, the rapid increase in the number of water bodies in 1995 should be correlated with the high deforestation rates observed in the same year. Indeed, 1995 is known for its deforestation peak partly due to the Plano Real launched in 1994 and which, due to a positive rate of exchange between the real and the US dollar, led to high soybean prices in Brazil encouraging farmers and multinational companies to invest in the region (Arvor et al., 2018). It is likely that the same reasons have also driven the construction of artificial dams to support the colonization process.

Secondly, the number of water bodies increased rapidly $(+50 \%$, from 347 to 522, mean values) between 2010 and 2015 whereas the cumulated area only increased moderately (+14\%, from 1494 to 1707 ha, mean values). It means that the numerous water bodies created during that period were quite small. Such situation may result from the non-application of the first inter-annual rule for year 2015 but, as mentioned in the previous section, the large number of Landsat images available for this year should have compensated for this issue. We thus think that this increase reveals tendencies on the recent development of numerous small excavated dams dedicated to fish farming, which could not be accurately delineated at Landsat scale but whose detection may be used as a proxy to observe the process of agricultural diversification in the southern Amazon.

\section{Discussion}

\subsection{On the classification methodology}

When compared to previous studies, the major asset of the proposed methodology is its automaticity, which raises promising perspectives for large-scale analysis (e.g. an entire watershed). In addition, the Landsat Spectral Classifier proposed by Baraldi et al. (2006) includes other spectral categories related to other land cover classes (e.g. about vegetation, soils, etc) which have been discarded from the analysis. We thus intend to extend this approach to other land cover types (e.g. especially forests). In this regard, the present work is a first part of an expected more complete system we wish to implement. But, for the moment, important limitations of the current approach should be discussed carefully.

First, the Landsat spatial resolution restricted the detection of small and linear water reservoirs. While such limitation did not impact too much on the estimated areas $(C A W B)$ at regional scale, it led to high overestimations of the number of water bodies (NumWB) when compared to the reference dataset. Nonetheless, it is worth noting that the number of water bodies in the reference dataset is underestimated since groups of water tanks are only counted once. Second, the method does not discriminate natural and artificial water bodies, nor the different types of artificial water reservoirs in the region (run-of-river farm dams and excavated reservoirs). Third, stored water volumes are not estimated while such information would be highly relevant to better understand the drivers of the observed dynamics.

These limitations could be (partially) addressed by using ancillary data (Digital Elevation Model for example (Donchyts et al., 2016; Shao et al., 2012)) and/or by computing empirical relationships relating reservoir extent and volume could be used (Jones et al., 2017). In addition, to adapt the approach to higher resolution images would also be of interest. The recent launch of the Sentinel2 mission with free access to $10 \mathrm{~m}$ resolution images every 5 days raises promising perspectives. The Landsat Spectral Classifier has been designed to be easily adapted to other optical images (SPOT, Ikonos, WorldView, etc Baraldi et al., 2010) and thus could also be adapted to Sentinel-2. A higher spatial resolution would then make it possible to adopt a Geographic Object-Based Image Analysis
(GEOBIA Blaschke, 2010; Blaschke and Strobl, 2001; Blaschke et al., 2014; Hay and Castilla, 2008). Taking into account other image features such as shape of image objects or spatial relations between objects should help to discriminate different types of artificial and natural water bodies. Fuzzy approaches (e.g. Linear Mixture Models) may also be relevant to detect small water bodies based on the probability for a pixel to belong to the "Water" class. Nonetheless, such an approach is difficult to automatize because it is complicated to identify pure endmembers for each image. Overall, it is not very robust because the efficiency of the unmixing also depends on the quality of the image, what is an issue when processing time series of heterogeneous images (e.g. high variability of cloud cover rates).

In addition, the method requires a large number of available images to limit the uncertainties. Indeed, in years with high cloud cover rates (i.e. with low values of NumObs index), cloud shadows may be assigned to a water class if the Fmask algorithm does not correctly delineate all cloud shadows. In this regard, Multi Temporal Cloud Detection algorithms (Hagolle et al., 2010) may be better adapted to our system, which is already based on the analysis of Landsat time series. Overall, the final water masks produced by the method do not all have the same reliability depending on the number of input Landsat images used to build the time series. Quality indices are thus necessary to better handle the uncertainties associated with the final classifications. In this regard, Grekousis et al. (2015) recommend the implementation of pixelbased accuracy metrics for regional land cover products. In the present study, such metric could be derived from a fine analysis of the relation between the classification accuracy and the number of observations, i.e. the probability to correctly classify a pixel depending on the NumObs index.

Finally, the validation procedure deserves to be discussed. Indeed, it is a complex issue because we only have references for the "water" class (e.g. small water bodies). We thus collected random samples of the "Land" class in $500 \mathrm{~m}$ buffers around the reference water reservoirs. By doing so, we limited the risk of commission errors (i.e. pixels detected as water instead of land) outside these buffers. But, if we had selected these "Land" samples in the entire study area, we would have potentially collected samples in rivers, thus leading to false commission errors (i.e. pixels correctly classified as "Water" since they correspond to rivers but considered as errors because originally identified as "Land" in the reference data set). To address this issue, it would have been necessary to also manually delineate the rivers in the reference dataset. But we then would have validated the potential of the classification to map all types of water bodies (including dams and rivers), not only the small artificial water bodies. In that case, the statistical results (Overall accuracy and kappa) would have been artificially increased because most "Water" samples would have been collected in rivers, which are larger than small dams and thus easier to detect. For these reasons, although imperfect, we consider the validation procedure we proposed as a least worst solution.

\subsection{On the socio-environmental implications}

Unlike the impacts of large hydropower dams, the cumulated effects of small artificial water reservoirs are widely understudied to date, especially in the Amazon. They depend on several characteristics (distribution, size, management, origin of water, etc) and their analysis thus represents a huge challenge for scientists (Deitch et al., 2013; Carluer et al., 2016; Epstein et al., 2013). Yet, they raise important socio-environmental issues which are presently actively calling the attention of the scientific community and the civil society. In Europe, for example, the Water Framework Directive led to the removal of run-of-river dams in spite of a still 
high demand for creating new reservoirs for agricultural purposes. Although the scientific literature on the topic is still limited (Carluer et al., 2016), we here list a (non-exhaustive) number of emerging issues that deserve to be discussed in the specific context of the Amazon basin.

\subsubsection{Hydrological implications}

Although the water reservoirs are usually small, their accumulation can affect river flows because the water collected is often used for irrigation and thus does not contribute to river flow (Habets et al., 2014). Additionally, stored water can evaporate (Goldbach and Kuttler, 2015; Fowe et al., 2015; Dubreuil and Girard, 2013) or seep (Glendenning et al., 2012), thus leading to a water loss for river network depending on the climate context and the local geological settings. Water stagnation and lamination in impoundments also modify stream water thermal variations due to temperature differences between input and output (Hutchinson, 1957; Walker, 1979). Such thermal changes, associated to the passage from a lotic to a lentic system, alter the oxygen water content (Cooke, 2005). Reservoirs are commonly nutrient and pollutant sinks at watershed scale (Passy et al., 2012) and can be affected by eutrophication (Oliver et al., 2014; Dauta et al., 1999). Downstream of the dams, the entire freshwater system is modified due to hydrological and sedimentological changes that can significantly affect the river morphology and habitats (Williams, 1975; Verstraeten and Poesen, 2000; Magilligan and Nislow, 2005).

\subsubsection{Ecological implications}

Biodiversity is affected by the hydrological and morphological modification and fragmentation of the freshwater systems. Runof-river dams can represent obstacles to species migration by limiting mobility, habitat changes, disturbance regime and water quality modification (for reviews see Bunn and Arthington (2002) and Nilsson (2005)).

\subsubsection{Climatic implications}

Water reservoirs are known to significantly produce greenhouse gas (Louis et al., 2000). Flooded forests (e.g. varzeas) have been pointed out as sources of greenhouse gas emissions in the Amazon (Fearnside, 1995). They are especially responsible for the release of methane in the atmosphere, whose global warming potential is 21 times greater than $\mathrm{CO}_{2}$ (Fearnside, 1995). Then, although the emissions from small water reservoirs are still limited when compared to other anthropogenic sources (e.g. deforestation), we argue that their additional impact should be taken into account when estimating the global emissions of greenhouse gases.

In addition to their impacts on climate change, the development of run-of-river dams may also hinder communities to adapt to climate change. In France, the ability to fill small farm dams in dry years was projected to decrease, thus becoming inefficient to supply water to farmers when needed (Habets et al., 2014). In northern Spain, reservoirs have affected the frequency and severity of hydrological droughts (Vicente-Serrano et al., 2017). In semi-arid northeastern Brazil, van Oel et al. (2017) have shown how hydrological droughts can continue well beyond meteorological droughts due to a dense network of surface water storage reservoirs. In the southern Amazon, the rainy season is expected to shorten (Fu et al., 2013; Arvor et al., 2017) and the frequency of extreme climate events is expected to increase (Marengo and Espinoza, 2016), as testified by the recent droughts (2005, 2010 and 2015). Assessing how the construction of numerous dams may exacerbate (or alleviate) the impacts of extreme climatic events at watershed scale remains an open issue.

\subsubsection{Social implications}

Water quality in intensive agricultural areas is affected by the high use of agrochemicals (Arvor et al., 2017). Although recent studies led in the state of Mato Grosso have shown that concentrations of nitrate and phosphate do not differ between forest and agricultural watersheds (Neill et al., 2013), the multiplication of farm dams acting as pollutant sinks can curve this result on the long-term. While the large use of agrochemicals has already been shown to affect human health in Brazil (Bombardi, 2016), additional studies to assess the impacts of farming fishes in potentially contaminated water reservoirs are necessary.

In addition, the construction of huge hydropower dams in the Amazon (e.g. the Belo Monte dam in the state of Para) had important social impacts for a long time (Fearnside, 1999; MAB, 2017). Since access to water is expected to become an ever more sensitive issue in a context of climate change, the expansion of small dams may also become a source of conflicts and should thus be controlled efficiently.

\section{Conclusions and final considerations}

We implemented an automatic methodology to classify small water bodies in the southern Amazon based on time series of Landsat images. The statistical results (Overall Accuracy $=0.872$; Kappa index $=0.745$ ) confirmed the efficiency of the methodology although the spatial resolution of Landsat images limited the detection of very small water reservoirs. We estimated that the cumulated area and the number of small water reservoirs increased more than tenfold (from 153 to 1707 ha) and more than fivefold (86 to 522) between 1985 and 2015.

The rapid proliferation of small artificial reservoirs in the southern Amazon is the result of (1) an agricultural intensification process involving the adoption of irrigation practices and (2) an agricultural diversification process based on fish farming. These processes were initiated by farmers to address some environmental (e.g. need to contain deforestation) and economic (e.g. need to limit economic vulnerability related to monoculture Arvor et al., 2009) challenges. Yet, the rapid expansion of water bodies raises new socio-environmental issues (hydrological, climatological, ecological, etc) that need to be addressed by the scientific community.

But analyzing the cumulated impacts of small water dams is a challenging task that implies to adopt a multisector perspective. In this regard, DeFries and Rosenzweig (2010) reinforced the need for an integrated, whole-landscape approach for tropical landscapes to achieve multiple objectives (e.g. environmental preservation, climate mitigation, food production). In the Amazon, the impacts of small water dams cannot be decoupled from deforestation, which still remains the main threat to the environment. For example, deforestation increases water flows, current velocities and sediment flux, which can in turn reshape stream morphology (Neill et al., 2013). From this point-of-view, the construction of well-planned run-of-river dams can help to regulate the hydrological network. In the same direction, as part of important efforts to support farmers to respect the environmental laws and promote a Low Carbon Agriculture in Brazil (Nepstad et al., 2014), farmers are encouraged to reforest degraded river banks with a long-term objective to restore ecological corridors, limit soil erosion and preserve water quality at landscape/watershed level. How anthropized hydrosystems can counteract or exacerbate both (1) the socio-environmental impacts of deforestation and intensive agriculture and (2) the efforts to control these impacts is an open issue. In this regard, the use of remote sensing data is essential to bring relevant observations to the scientific community (hydrologists, ecologists, etc). The automatic method introduced in this paper is 
a first step in that direction which should now be pursued with finer analysis at regional or watershed level.

\section{Acknowledgments}

The authors wish to thank the (1) Rennes Metropole which funded an "Allocation d'Installation Scientifique", (2) the European Union which funded the H2020-MSCA-RISE-2015 ODYSSEA project (Project Reference: 691053), (3) the French National Agency for Research (ANR) which funded the DURAMAZ2 project (grant agreement ANR-11-BSH1-0003) and (4) the CAPES/COFECUB program which funded the GeoABC project (Methodologies and technological innovation for satellite monitoring of low carbon agriculture in support to Brazil's ABC Plan, project No. 845/15).

\section{References}

Acharya, T., Lee, D., Yang, I., Lee, J., 2016. Identification of water bodies in a Landsat 8 OLI Image using a J48 decision tree. Sensors 16, 1075.

Adams, W., Hughes, F., 1986. The environmental effects of dam construction in tropical africa: Impacts and planning procedures. Geoforum 17, 403-410.

Arvor, D., Dubreuil, V., Mendez, P., Ferreira, C.M., Meirelles, M., 2009. Développement, crises et adaptation des territoires du soja au Mato Grosso: l'exemple de Sorriso. Confins 6.

Arvor, D., Meirelles, M., Dubreuil, V., Bégué, A., Shimabukuro, Y.E., 2012. Analyzing the agricultural transition in Mato Grosso, Brazil, using satellite-derived indices. Appl. Geogr. 32, 702-713.

Arvor, D., Dubreuil, V., Simões, M., Bgu, A., 2013. Mapping and spatial analysis of the soybean agricultural frontier in Mato Grosso, Brazil, using remote sensing data. GeoJournal 78, 833-850.

Arvor, D., Tritsch, I., Barcellos, C., Jégou, N., Dubreuil, V., 2017. Land use sustainability on the south-eastern amazon agricultural frontier: recent progress and the challenges ahead. Appl. Geogr. 80, 86-97.

Arvor, D., Funatsu, B., Michot, V., Dubreuil, V., 2017. Monitoring rainfall patterns in the Southern Amazon with PERSIANN-CDR data: long-term characteristics and trends. Remote Sens. 9, 889.

Arvor, D., Daugeard, M., Tritsch, I., De Mello-Thery, N.A., Thery, H., Dubreuil, V., 2018. Combining socioeconomic development with environmental governance in the Brazilian Amazon: the Mato Grosso agricultural frontier at a tipping point. Environ. Dev. Sustain. 20, 1-22.

Baraldi, A., Puzzolo, V., Blonda, P., Bruzzone, L., Tarantino, C., 2006. Automatic spectral rule-based preliminary mapping of calibrated Landsat TM and ETM+ Images. IEEE Trans. Geosci. Remote Sens. 44, 2563-2586.

Baraldi, A., Durieux, L., Simonetti, D., Conchedda, G., Holecz, F., Blonda, P., 2010. Automatic spectral-rule-based preliminary classification of radiometrically calibrated SPOT-4/-5/IRS, AVHRR/MSG, AATSR, IKONOS/QuickBird/OrbView/ GeoEye, and DMC/SPOT-1/-2 Imagery;Part I: System design and implementation. IEEE Trans. Geosci. Remote Sens. 48, 1299-1325.

Barrow, C.J., 1987. The environmental impacts of the tucuri dam on the middle and lower tocantins river basin, brazil. Regul. Rivers: Res. Manage. 1, 49-60.

Bhagat, V.S., Sonawane, K.R., 2011. Use of Landsat ETM+ data for delineation of water bodies in hilly zones. J. Hydroinformatics 13, 661-671.

Blaschke, T., 2010. Object based image analysis for remote sensing. ISPRS J. Photogramm. Remote Sens. 65, 2-16.

Blaschke, T., Strobl, J., 2001. Whats wrong with pixels? Some recent developments interfacing remote sensing and GIS. Interfacing Remote Sens. GIS 6, 12-17.

Blaschke, T., Hay, G.J., Kelly, M., Lang, S., Hofmann, P., Addink, E., Queiroz Feitosa, R., van der Meer, F., van der Werff, H., van Coillie, F., Tiede, D., 2014. Geographic object-based image analysis towards a new paradigm. ISPRS J. Photogramm. Remote Sens. 87, 180-191.

Bombardi, L.M., 2016, Pequeno Ensaio Cartografico Sobre o Uso de Agrotoxicos no Brasil, USP, So Paulo.

Bunn, S.E., Arthington, A.H., 2002. Basic principles and ecological consequences of altered flow regimes for aquatic biodiversity. Environ. Manage. 30, 492-507.

Callow, J., Smettem, K., 2009. The effect of farm dams and constructed banks on hydrologic connectivity and runoff estimation in agricultural landscapes. Environ. Modell. Softw. 24, 959-968.

Campari, J.S., 2005. The economics of deforestation in the Amazon: dispelling the myths, Elgar, Cheltenham. OCLC: 260086594.

Carluer, N., Babut, M., Belliard, J., Bernez, I., Burger Leenhardt, D., Dorioz, J.M., Douez, O., Dufour, S., Grimaldi, C., Habets, F., Le Bissonnais, Y., Molnat, J., Rollet, A.J., Rosset, V., Sauvage, S., Usseglio-Polatera, P., Leblanc, B., 2016. Expertise scientifique collective sur limpact cumul des retenues, Rapport de synthse, IRSTEA - AFB.

Carreiras, J.M.B., Jones, J., Lucas, R.M., Gabriel, C., 2014. Land use and land cover change dynamics across the brazilian amazon: insights from extensive timeseries analysis of remote sensing data. PLoS ONE 9, e104144.

Caviglia-Harris, J., Sills, E., Bell, A., Harris, D., Mullan, K., Roberts, D., 2016. Busting the Boom-Bust pattern of development in the Brazilian Amazon. World Dev. 79, 82-96.
Chander, G., Markham, B.L., Helder, D.L., 2009. Summary of current radiometric calibration coefficients for Landsat MSS, TM, ETM+, and EO-1 ALI sensors. Remote Sens. Environ. 113, 893-903.

Congalton, R.G., 1991. A review of assessing the accuracy of classifications of remotely sensed data. Remote Sens. Environ. 37, 35-46.

Cooke, G.D. (Ed.), 2005. Restoration and Management of Lakes and Reservoirs. third ed. CRC Press, Boca Raton, FL.

Cudennec, C., Sarraza, M., Nasri, S., 2004. Modélisation robuste de l'impact agrégé de retenues collinaires sur l'hydrologie de surface. Revue des sciences de l'eau 17, $181-194$.

Dauta, A., Lapaquellerie, Y., Maillet, N., 1999. Role of the dams on the river lot on two types of pollution:point-sources (cadmium) and non-point sources (phosphorus). In: Garnier, J., Mouchel, J.-M. (Eds.), Man and River Systems. Springer, Netherlands, pp. 325-329. https://doi.org/10.1007/978-94-017-21639_34.

DeFries, R., Rosenzweig, C., 2010. Toward a whole-landscape approach for sustainable land use in the tropics. Proc. Nat. Acad. Sci. 107, 19627-19632.

Deitch, M.J., Merenlender, A.M., Feirer, S., 2013. Cumulative effects of small reservoirs on streamflow in northern coastal california catchments. Water Resour. Manage. 27, 5101-5118.

de Toledo, C.E., de Arajo, J.C., de Almeida, C.L., 2014. The use of remote-sensing techniques to monitor dense reservoir networks in the brazilian semiarid region. Int. J. Remote Sens. 35, 3683-3699.

Donchyts, G., Schellekens, J., Winsemius, H., Eisemann, E., van de Giesen, N., 2016. A $30 \mathrm{~m}$ resolution surface water mask including estimation of positional and thematic differences using Landsat 8, SRTM and OpenStreetMap: a case study in the Murray-Darling Basin, Australia. Remote Sens. 8, 386.

Dubreuil, P., Girard, G., 2013. Influence of a very large number of small reservoirs on the annual flow regime of a tropical stream. In: Ackermann, W.C., White, G.F., Worthington, E., Ivens, J.L. (Eds.), Geophysical Monograph Series. American Geophysical Union, pp. 295-299. https://doi.org/10.1029/GM017p0295.

Dudgeon, D., 2000. Large-scale hydrological changes in tropical asia: prospects for riverine biodiversity. Bioscience 50, 793-806.

Epstein, D.M., Neilson, B.T., Goodman, K.J., Stevens, D.K., Wurtsbaugh, W.A., 2013. A modeling approach for assessing the effect of multiple alpine lakes in sequence on nutrient transport. Aquat. Sci. 75, 199-212.

FAMATO, 2014. IMEA, Diagnóstico da Piscicultura em Mato Grosso, Technical Report, Federaç ao da Agricultura e Pecuária do Estado do Mato Grosso and Instituto Mato-Grossense de Economia Agropecuária, Cuiabá-MT.

Fearnside, P.M., 1995. Hydroelectric dams in the Brazilian Amazon as sources of greenhouse gases. Environ. Conserv. 22, 7-19.

Fearnside, P.M., 1999. Social impacts of Brazil's Tucuru Dam. Environ. Manage. 24, 483-495.

Fearnside, P.M., 2001. Soybean cultivation as a threat to the environment in Brazil Environ. Conserv. 28, 23-38.

Fearnside, P.M., 2001. Environmental impacts of brazil's tucuru dam: unlearned lessons for hydroelectric development in amazonia. Environ. Manage. 27, $377-$ 396.

Fearnside, P.M., 2006. Dams in the amazon: Belo monte and Brazils hydroelectric development of the Xingu river basin. Environ. Manage. 38, 16-27.

Fowe, T., Karambiri, H., Paturel, J.-E., Poussin, J.-C., Cecchi, P., 2015. Water balance of small reservoirs in the volta basin: a case study of boura reservoir in burkina faso. Agric. Water Manage. 152, 99-109.

Fu, R., Yin, L., Li, W., Arias, P.A., Dickinson, R.E., Huang, L., Chakraborty, S., Fernandes, K., Liebmann, B., Fisher, R., Myneni, R.B., 2013. Increased dry-season length over southern Amazonia in recent decades and its implication for future climate projection. PNAS 110, 18110-18115.

Galford, G.L., Soares-Filho, B., Cerri, C.E.P., 2013. Prospects for land-use sustainability on the agricultural frontier of the Brazilian Amazon. Philos. Trans. Roy. Soc. B: Biol. Sci. 368, 20120171.

Gibbs, H.K., Rausch, L., Munger, J., Schelly, I., Morton, D.C., Noojipady, P., SoaresFilho, B., Barreto, P., Micol, L., Walker, N.F., 2015. Brazil's soy moratorium. Science 347, 377-378.

Glendenning, C., van Ogtrop, F., Mishra, A., Vervoort, R., 2012. Balancing watershed and local scale impacts of rain water harvesting in india: a review. Agric. Water Manage. 107, 1-13.

Goldbach, A., Kuttler, W., 2015. Turbulent heat fluxes above a suburban reservoir: a case study from Germany. J. Hydrometeorol. 16, 244-260.

Gómez, C., White, J.C., Wulder, M.A., 2016. Optical remotely sensed time series data for land cover classification: a review. ISPRS J. Photogramm. Remote Sens. 116 55-72.

Grekousis, G., Mountrakis, G., Kavouras, M., 2015. An overview of 21 global and 43 regional land-cover mapping products. Int. J. Remote Sens. 36, 1-27.

Gütner, A., Krol, M.S., Araújo, J.C.D., Bronstert, A., 2004. Simple water balance modelling of surface reservoir systems in a large data-scarce semiarid region/ Modlisation simple du bilan hydrologique de systmes de rservoirs de surface dans une grande rgion semi-aride pauvre en donnes. Hydrol. Sci. J. 49.

Habets, F., Philippe, E., Martin, E., David, C.H., Leseur, F., 2014. Small farm dams: impact on river flows and sustainability in a context of climate change. Hydrol. Earth Syst. Sci. 18, 4207-4222.

Hagolle, O., Huc, M., Pascual, D.V., Dedieu, G., 2010. A multi-temporal method for cloud detection, applied to FORMOSAT-2, VENS, LANDSAT and SENTINEL-2 images. Remote Sens. Environ. 114, 1747-1755.

Hansen, M.C., Loveland, T.R., 2012. A review of large area monitoring of land cover change using Landsat data. Remote Sens. Environ. 122, 66-74. 
Hansen, M.C., Potapov, P.V., Moore, R., Hancher, M., Turubanova, S.A., Tyukavina, A., Thau, D., Stehman, S.V., Goetz, S.J., Loveland, T.R., Kommareddy, A., Egorov, A Chini, L., Justice, C.O., Townshend, J.R.G., 2013. High-resolution global maps of 21st-century forest cover change. Science 342, 850-853.

Hay, G.J., Castilla, G., 2008. Geographic Object-Based Image Analysis (GEOBIA): a new name for a new discipline. In: Blaschke, T., Lang, S., Hay, G.J. (Eds.), ObjectBased Image Analysis. Springer, Berlin, Heidelberg, pp. 75-89.

Hughes, D.A., Mantel, S.K., 2010. Estimating the uncertainty in simulating the impacts of small farm dams on streamflow regimes in South Africa. Hydrol. Sci. J. $55,578-592$.

Hutchinson, G.E., 1957. Concluding remarks. Cold Spring Harb. Symp. Quant. Biol. $22,415-427$

IBGE, 2017. Instituto Brasileiro de Geografia e Estatistica.

Inglada, J., Vincent, A., Arias, M., Tardy, B., Morin, D., Rodes, I., 2017. Operational high resolution land cover map production at the country scale using satellite image time series. Remote Sens. 9, 95.

INPE, 2017. Taxas anuais do desmatamento - 1988 até 2015.

Irons, J.R., Dwyer, J.L., Barsi, J.A., 2012. The next Landsat satellite: the Landsat data continuity mission. Remote Sens. Environ. 122, 11-21.

Jones, S., Fremier, A., DeClerck, F., Smedley, D., Pieck, A.O., Mulligan, M., 2017. Big data and multiple methods for mapping small reservoirs: comparing accuracies for applications in agricultural landscapes. Remote Sens. 9, 1307.

Kastens, J.H., Brown, J.C., Coutinho, A.C., Bishop, C.R., Esquerdo, J.C.D.M., 2017. Soy moratorium impacts on soybean and deforestation dynamics in Mato Grosso, Brazil. PLOS ONE 12, e0176168.

Ko, B., Kim, H., Nam, J., 2015. Classification of potential water bodies using Landsat 8 OLI and a combination of two boosted random forest classifiers. Sensors 15 , 13763-13777.

Latrubesse, E.M., Arima, E.Y., Dunne, T., Park, E., Baker, V.R., dHorta, F.M., Wight, C., Wittmann, F., Zuanon, J., Baker, P.A., Ribas, C.C., Norgaard, R.B., Filizola, N., Ansar, A., Flyvbjerg, B., Stevaux, J.C., 2017. Damming the rivers of the amazon basin. Nature 546, 363-369.

Lehner, B., Liermann, C.R., Revenga, C., Vrsmarty, C., Fekete, B., Crouzet, P., Dll, P., Endejan, M., Frenken, K., Magome, J., Nilsson, C., Robertson, J.C., Rdel, R., Sindorf, N., Wisser, D., 2011. High-resolution mapping of the world's reservoirs and dams for sustainable river-flow management. Front. Ecol. Environ. 9, 494-502.

Louis, V.L. St., Kelly, C.A., Duchemin, É., Rudd, J.W.M., Rosenberg, D.M., 2000. Reservoir surfaces as sources of greenhouse gases to the atmosphere: a global estimate. Bioscience 50, 766-775.

Lowe, L., Nathan, R., Morden, R., 2005. Assessing the impact of farm dams on streamflows, part II: Regional characterisation. Aust. J. Water Resources 9, 13 26.

MAB, 2017. Movimento dos atingidos por barragens.

Macedo, M.N., DeFries, R.S., Morton, D.C., Stickler, C.M., Galford, G.L., Shimabukuro, Y.E., 2012. Decoupling of deforestation and soy production in the southern Amazon during the late 2000s. Proc. Nat. Acad. Sci. 109, 1341-1346.

Magilligan, F.J., Nislow, K.H., 2005. Changes in hydrologic regime by dams. Geomorphology 71, 61-78.

Maingi, J.K., Marsh, S.E., 2002. Quantifying hydrologic impacts following dam construction along the tana river, kenya. J. Arid Environ. 50, 53-79.

Malveira, V.T.C., de Araújo, J.C., Güntner, A., 2012. Hydrological impact of a highdensity reservoir network in semiarid northeastern Brazil. J. Hydrol. Eng. 17, 109-117.

Mamede, G.L., Araujo, N.A.M., Schneider, C.M., de Araujo, J.C., Herrmann, H.J., 2012 Overspill avalanching in a dense reservoir network. Proc. Nat. Acad. Sci. 109 7191-7195.

Marceau, D.J., Howarth, P.J., Gratton, D.J., 1994. Remote sensing and the measurement of geographical entities in a forested environment. 1. The scale and spatial aggregation problem. Remote Sens. Environ. 49, 93-104.

Marengo, J.A., Espinoza, J.C., 2016. Extreme seasonal droughts and floods in Amazonia: causes, trends and impacts: extremes in AMAZONIA. Int. J. Climatol. 36, 1033-1050.

Morton, D.C., DeFries, R.S., Shimabukuro, Y.E., Anderson, L.O., Arai, E., Espirito-Santo F.d.B., Freitas, R., Morisette, J., 2006. Cropland expansion changes deforestation dynamics in the southern Brazilian Amazon. Proc. Nat. Acad. Sci. 103, $14637-$ 14641.

Nathan, R., Lowe, L., 2012. The hydrologic impacts of farm dams. Aust. J. Water Resources 16, 75-83.

Neill, C., Coe, M.T., Riskin, S.H., Krusche, A.V., Elsenbeer, H., Macedo, M.N. McHorney, R., Lefebvre, P., Davidson, E.A., Scheffler, R., Figueira, A.M. e. S. Porder, S., Deegan, L.A., 2013. Watershed responses to amazon soya bean cropland expansion and intensification. Philos. Trans. Roy. Soc. B: Biol. Sci. 368 , 20120425.

Nepstad, D.C., Stickler, C.M., Almeida, O.T., 2006. Globalization of the Amazon soy and beef industries: opportunities for conservation. Conserv. Biol. 20, 15951603.

Nepstad, D., Soares-Filho, B.S., Merry, F., Lima, A., Moutinho, P., Carter, J., Bowman, M., Cattaneo, A., Rodrigues, H., Schwartzman, S., McGrath, D.G., Stickler, C.M.
Lubowski, Piris-Cabezas, P., Rivero, S., Alencar, A., Almeida, O., Stella, O., 2009. The end of deforestation in the Brazilian Amazon. Science 326, 1350-1351.

Nepstad, D., McGrath, D., Stickler, C., Alencar, A., Azevedo, A., Swette, B., Bezerra, T., DiGiano, M., Shimada, J., Seroa da Motta, R., Armijo, E., Castello, L., Brando, P., Hansen, M.C., McGrath-Horn, M., Carvalho, O., Hess, L., 2014. Slowing Amazon deforestation through public policy and interventions in beef and soy supply chains. Science 344, 1118-1123.

Nilsson, C., 2005. Fragmentation and flow regulation of the world's large river systems. Science 308, 405-408.

Oliver, A.A., Dahlgren, R.A., Deas, M.L., 2014. The upside-down river: reservoirs, algal blooms, and tributaries affect temporal and spatial patterns in nitrogen and phosphorus in the klamath river, USA. J. Hydrol. 519, 164-176.

Passy, P., Garnier, J., Billen, G., Fesneau, C., Tournebize, J., 2012. Restoration of ponds in rural landscapes: modelling the effect on nitrate contamination of surface water (the seine river basin, France). Sci. Tot. Environ. 430, 280-290.

Pekel, J.-F., Cottam, A., Gorelick, N., Belward, A.S., 2016. High-resolution mapping of global surface water and its long-term changes. Nature 540, 418-422.

Powers, S.M., Robertson, D.M., Stanley, E.H., 2014. Effects of lakes and reservoirs on annual river nitrogen, phosphorus, and sediment export in agricultural and forested landscapes: effects of lakes and reservoirs on river nutrients and sediment. Hydrol. Process. 28, 5919-5937.

Ramireddygari, S., Sophocleous, M., Koelliker, J., Perkins, S., Govindaraju, R., 2000. Development and application of a comprehensive simulation model to evaluate impacts of watershed structures and irrigation water use on streamflow and groundwater: the case of Wet Walnut Creek Watershed, Kansas, USA. J. Hydrol. 236, 223-246.

Rodrigues, L.N., Sano, E.E., Steenhuis, T.S., Passo, D.P., 2012. Estimation of small reservoir storage capacities with remote sensing in the Brazilian Savannah Region. Water Resour. Manage 26, 873-882.

Rudorff, B.F.T., Adami, M., Aguiar, D.A., Moreira, M.A., Mello, M.P., Fabiani, L., Amaral, D.F., Pires, B.M., 2011. The soy moratorium in the Amazon biome monitored by remote sensing images. Remote Sens. 3, 185-202.

Santucci, V.J., Gephard, S.R., Pescitelli, S.M., 2005. Effects of multiple low-head dams on fish, macroinvertebrates, habitat, and water quality in the fox river, illinois. North Am. J. Fish. Manage. 25, 975-992.

Shao, Q., Chan, C., Jin, H., Barry, S., 2012. Statistical justification of hillside farm dam distribution in Eastern Australia. Water Resour. Manage. 26, 3139-3151.

She, X., Zhang, L., Cen, Y., Wu, T., Huang, C., Baig, M.H.A., 2015. Comparison of the continuity of vegetation indices derived from landsat 8 oli and landsat 7 etm+ data among different vegetation types. Remote Sens. 7, 13485-13506.

Stevaux, J.C., Martins, D.P., Meurer, M., 2009. Changes in a large regulated tropical river: the paran river downstream from the porto primavera dam, brazil. Geomorphology 113, 230-238.

Tritsch, I., Arvor, D., 2016. Transition in environmental governance in the Brazilian Amazon: emergence of a new pattern of socio-economic development and deforestation. Land Use Policy 59, 446-455.

Tulbure, M.G., Broich, M., 2013. Spatiotemporal dynamic of surface water bodies using Landsat time-series data from 1999 to 2011. ISPRS J. Photogramm. Remote Sens. 79, 44-52.

USGS, 2016. Landsat 8 (L8) Data Users Handbook, Technical Report, USGS, Sioux Falls, USA.

van Oel, P.R., Martins, E.S., Costa, A.C., 2017. The effect of reservoir networks on drought propagation, Athens, 10th WORLD CONGRESS on water resources and environment, Greece, p. 7.

VanWey, L.K., Spera, S., Sa, R.d., Mahr, D., Mustard, J.F., 2013. Socioeconomic development and agricultural intensification in Mato Grosso. Philos. Trans. Roy. Soc. B: Biol. Sci. 368, 20120168.

Verstraeten, G., Poesen, J., 2000. Estimating trap efficiency of small reservoirs and ponds: methods and implications for the assessment of sediment yield. Prog. Phys. Geogr. 24, 219-251.

Vicente-Serrano, S., Zabalza-Martnez, J., Borrs, G., Lpez-Moreno, J., Pla, E., Pascual, D., Sav, R., Biel, C., Funes, I., Azorin-Molina, C., Sanchez-Lorenzo, A., MartnHernndez, N., Pea-Gallardo, M., Alonso-Gonzlez, E., Tomas-Burguera, M., Kenawy, A.E., 2017. Extreme hydrological events and the influence of reservoirs in a highly regulated river basin of northeastern spain. J. Hydrol.: Region. Stud. 12, 13-32.

Waldner, F., Canto, G.S., Defourny, P., 2015. Automated annual cropland mapping using knowledge-based temporal features. ISPRS J. Photogramm. Remote Sens. $110,1-13$.

Walker, K.F., 1979. Regulated streams in australia: the murray-darling river system. In: Ward, J.V., Stanford, J.A. (Eds.), The Ecology of Regulated Streams. Springer, US, pp. 143-163. https://doi.org/10.1007/978-1-4684-8613-1_9.

Weinhold, D., Reis, E.J., Vale, P.M., 2015. Boom-bust patterns in the Brazilian Amazon. Glob. Environ. Change 35, 391-399.

Williams, J.R., 1975. Sediment routing for agricultural watersheds. J. Am. Water Resour. Assoc. 11, 965-974.

Zhu, Z., Woodcock, C.E., 2012. Object-based cloud and cloud shadow detection in Landsat imagery, Remote Sens, Environ. 118, 83-94. 